\title{
Increased Sphingosine-I-Phosphate Serum Concentrations in Subjects with Periodontitis: A Matter of Inflammation
}

\author{
Eileen Moritz, ${ }^{1,2, *}$ \\ Gabriele Jedlitschky, ${ }^{1} *$ \\ Josefine Negnal,' \\ Mladen V Tzvetkov, \\ Günter Daum, ${ }^{3,4}$ \\ Marcus Dörr, (D) $^{2,5}$ \\ Stephan B Felix, 2,5 \\ Henry Völzke, ${ }^{2,6}$ \\ Matthias Nauck, 2,7 \\ Edzard Schwedhelm, (1D ${ }^{4,8}$ \\ Peter Meisel, ${ }^{9}$ Thomas Kocher, \\ Bernhard H Rauch, (D) ${ }^{1,2,10, *}$ \\ Birte Holtfreter ${ }^{9}$ ** \\ 'Institute of Pharmacology, Department of \\ General Pharmacology, University Medicine \\ Greifswald, Greifswald, Germany; ${ }^{2}$ German \\ Center for Cardiovascular Research (DZHK) \\ Partner Site Greifswald, Greifswald, Germany; \\ ${ }^{3}$ Clinic and Polyclinic for Vascular Medicine, \\ University Heart Center, University Medical \\ Center Hamburg-Eppendorf, Hamburg, Germany; \\ ${ }^{4}$ German Center for Cardiovascular Research \\ (DZHK), Partner Site Hamburg/Kiel/Lübeck, \\ Hamburg, Germany; ${ }^{5}$ Department of Interna \\ Medicine B, University Medicine Greifswald, \\ Greifswald, Germany; ${ }^{6}$ Institute for Community \\ Medicine, University Medicine Greifswald, \\ Greifswald, Germany; ${ }^{7}$ Institute of Clinical \\ Chemistry and Laboratory Medicine, University \\ Medicine Greifswald, Greifswald, Germany; \\ ${ }_{8}^{8}$ Institute of Clinical Pharmacology and Toxicology, \\ University Medical Center Hamburg-Eppendorf, \\ Humburg, Germany; ${ }^{2}$ Dental Clinics, Department \\ of Periodontology, University Medicine Greifswald \\ Greifswald, Germany; ${ }^{10} \mathrm{Carl}$ von Ossietzky \\ Universität Oldenburg, Department of Human \\ Medicine, Section of Pharmacology and Toxicology, \\ Oldenburg, Germany \\ *These authors contributed equally to this work
}

Correspondence: Bernhard H Rauch

Carl von Ossietzky Universität

Oldenburg, Department of Human

Medicine, Section of Pharmacology and

Toxicology, Carl-von-Ossietzky-Str. 9-II,

Oldenburg, 26I29, Germany

Tel +49 (0) 44I 7984930

$\mathrm{Fax}+49(0) 4417983088$

Email Bernhard.Rauch@uni-oldenburg.de
Purpose: Periodontitis is an inflammatory disease of the oral cavity with an alarmingly high prevalence within the adult population. The signaling lipid sphingosine-1-phosphate (S1P) plays a crucial role in inflammatory and immunomodulatory responses. In addition to cardiovascular disease, sepsis and tumor entities, S1P has been recently identified as both mediator and biomarker in osteoporosis. We hypothesized that S1P may play a role in periodontitis as an inflammation-prone bone destructive disorder. The goal of our study was to evaluate associations between periodontitis and S1P serum concentrations in the Study of Health in Pomerania (SHIP)-Trend cohort. In addition, we investigated the expression of S1P metabolizing enzymes in inflamed gingival tissue.

Patients and Methods: We analyzed data from 3371 participants (51.6\% women) of the SHIP-Trend cohort. Periodontal parameters and baseline characteristics were assessed. Serum S1P was measured by liquid chromatography tandem mass spectrometry. The expression of S1P metabolizing enzymes was determined by immunofluorescence staining of human gingival tissue.

Results: S1P serum concentrations were significantly increased in subjects with both moderate and severe periodontitis, assessed as probing depth and clinical attachment loss. In contrast, no significant association of S1P was seen with caries variables (number and percentage of decayed or filled surfaces). S1P concentrations significantly increased with increasing high-sensitivity C-reactive protein (hs-CRP) levels. Interestingly, inflamed compared to normal human gingival tissue exhibited elevated expression levels of the S1Pgenerating enzyme sphingosine kinase 1 (SphK1).

Conclusion: We report an intriguingly significant association of various periodontal parameters with serum levels of the inflammatory lipid mediator S1P. Our data point towards a key role of S1P during periodontitis pathology. Modulation of local S1P levels or its signaling properties may represent a potential future therapeutic strategy to prevent or to retard periodontitis progression and possibly reduce periodontitis-related tooth loss.

Keywords: sphingosine-1-phosphate, lipid mediator, periodontitis, inflammation

\section{Introduction}

Periodontitis is an inflammatory disease characterized by destruction of the supporting structures of the teeth, ie, the periodontium which consists of the gingiva, periodontal ligament, cementum and alveolar bone. Gingival bleeding and recession, periodontal pocket formation as well as loosening and eventual loss of teeth represent typical symptoms of periodontitis. ${ }^{1}$ The worldwide prevalence of severe 
periodontitis over the last 20 years is estimated at consistently $11 \%$. $^{2}$ Although in Germany the prevalence of moderate or severe periodontitis has generally declined over the past 20 years, it is still alarmingly high within the adult population. ${ }^{3-6}$ Periodontitis also triggers low-grade systemic inflammation, ${ }^{7,8}$ thereby contributing to ischemic pathologies such as atherosclerosis ${ }^{9}$ manifesting in coronary heart, cerebrovascular and peripheral artery disease. ${ }^{10-12}$ Mainly discussed pathways include a direct one via spillover of periopathogenic bacteria into the bloodstream, ${ }^{13}$ which in turn provoke an immune response, and an indirect one via induction of increased levels of locally produced pro-inflammatory cytokines. ${ }^{7}$

Sphingosine-1-phosphate (S1P) is a signaling lipid involved in numerous biological processes such as inflammatory and immunomodulatory responses. ${ }^{14,15} \mathrm{~S} 1 \mathrm{P}$ is generated intracellularly by the sphingosine kinases SphK1 and SphK2 from sphingosine. Reversely, the S1P phosphatases SPP1 and SPP2 dephosphorylate it to sphingosine, whereas the S1P lyase (SPL) irreversibly degrades S1P into hexadecenal and phosphoethanolamine. ${ }^{16}$ After secretion from S1P-generating cells, S1P regulates various cell functions via a family of 5 G-protein-coupled receptors S1PR1-5. ${ }^{16-18}$ Circulating S1P in blood is derived mostly from platelets, erythrocytes, and endothelial cells and is mainly bound to the high-density lipoprotein-associated apolipoprotein $\mathrm{M}(70 \%)$ and to albumin (30\%). ${ }^{17,19-21}$ Recently, S1P has emerged as prognostic biomarker, eg, for cardiovascular disease ${ }^{22}$ and sepsis. ${ }^{23}$ Consequently, reference values for S1P in serum have been defined based on a sample of 1339 healthy participants of the Study of Health in Pomerania (SHIP-Trend) cohort. The overall serum reference interval ranges from 0.534 to $1.242 \mu \mathrm{mol} / \mathrm{L}$ (2.5th; 97.5th percentile) with a median S1P concentration of $0.804 \mu \mathrm{mol} / \mathrm{L}$, which was irrespective of age, gender, body mass index (BMI) or smoking status. ${ }^{24,25}$

In the context of bone destructive disorders, S1P mobilizes osteoclast precursor cells and regulates bone mineral homeostasis via S1PRs during osteoporosis. ${ }^{26}$ In particular, S1P has been recently identified as both mediator and biomarker in osteoporosis. ${ }^{27}$ Experimental inhibition of the S1P-degrading SPL led to increased bone formation, mass and strength in different mice models of osteoporosis. ${ }^{27}$ Furthermore, S1P serum concentrations were positively associated with bone formation markers, but not with resorption markers in the SHIP-Trend cohort. $^{27}$ Given this recently revealed function in modulating bone formation and since S1P is a key mediator of inflammatory responses, we hypothesized that it may also play a role in inflammation-prone bone destructive disorders such as periodontitis. However, no epidemiological data addressing the impact of S1P on periodontitis severity have been reported to date.

Therefore, the aim of the present study was to evaluate associations between periodontitis severity as well as extent and S1P serum concentrations in 3371 participants of the SHIP-Trend cohort. In addition, we investigated the expression of S1P metabolizing enzymes in inflamed human gingival tissue.

\section{Materials and Methods Study Population and Derivation of Samples}

SHIP-Trend is the second independent population-based cohort of the Studies of Health in Pomerania (SHIP) with the study region of West Pomerania, a rural region in the northeast of Germany. ${ }^{28}$ Sample selection was performed using local population registries in the Federal State of Mecklenburg-West Pomerania. A random sample of 8826 adults aged 20-82 years was drawn, stratified by gender, age and city/county of residence. Of all subjects invited, 4420 individuals (50.1\%), 2145 men and 2275 women, participated in the examinations between 2008 and 2012. ${ }^{29}$ All participants provided informed written consent. The study conformed to the principles of the Declaration of Helsinki and was approved by the Ethics Committee of the University of Greifswald (BB 39/08).

Of the 4420 participants, 4052 subjects $(91.7 \%)$ participated in the dental examinations. Of these, 681 with missing data for S1P (215) and/or probing depth (PD; 410 ) and/or the confounders (smoking, diabetes mellitus, hemoglobin, waist-to-hip-ratio, obesity; 56) were excluded from the analyses resulting in a final study population of 3371 (1739 female and 1632 male) individuals (see flowchart in Supplemental Figure 1).

\section{Assessment of Covariates}

Information on gender, age, socio-demographic characteristics (school education; <10/10/>10 years), smoking habits (never smoker, former smoker with $<20$ pack years, former smoker with $\geq 20$ pack years, current smoker with $<20$ pack years, current smoker with $\geq 20$ pack years) and medical histories were collected by computer-assisted personal interviews. Body height was measured to the 
nearest $0.1 \mathrm{~cm}$ and weight to the nearest $0.1 \mathrm{~kg}$. BMI was calculated as weight $[\mathrm{kg}]$ divided by height ${ }^{2}\left[\mathrm{~m}^{2}\right]$. Waist circumference and hip circumference were measured using an inelastic tape with the subject standing comfortably with weight distributed evenly on both feet. Waist circumference was measured midway between the lower rib margin and the iliac crest in the horizontal plane. Hip circumference was determined as the greatest circumference between the highest point of the iliac crest and the crotch. Waist-to-hip ratio was calculated from the respective measures. Diabetes mellitus was defined based on a physician's diagnosis or intake of anti-diabetic medication (Anatomical Therapeutic Chemical Classification System [ATC] code A10). Medication with statins (ATC code $\mathrm{C10AA}$ ), acetylsalicylic acid as platelet aggregation inhibitor (ATC code B01AC06), cortisone (ATC codes H02A and H02B), or systemic antibiotics (ATC code J01) was assessed.

Blood samples were taken from the cubital vein of participants in the supine position. HbAlc was measured by high-performance liquid chromatography with spectrophotometric detection (Diamat Analyzer; Bio-Rad, Munich, Germany) and a coefficient of variation of $1.5 \%$. High-sensitivity C-reactive protein (hs-CRP) concentrations were determined in serum by nephelometry on the Dimension VISTA (Siemens Healthcare Diagnostics, Eschborn, Germany).

\section{Periodontal Examination}

Clinical attachment loss (CAL) and PD were determined with a periodontal probe (SHIP-Trend: PCPUNC 15, HuFriedy, Chicago, IL, USA) at distobuccal, midbuccal, mesiobuccal, and midlingual/midpalatal sites according to the half-mouth method excluding third molars (left or right side randomly selected). Measurements were mathematically rounded to the next whole millimeter. PD was measured as the distance between free gingival margin (FGM) and pocket base. If the cemento-enamel junction (CEJ) was located sub-gingivally, CAL was determined as PD minus the distance between FGM and CEJ. If recession was present at the examined site, CAL was directly assessed as the distance between CEJ and pocket base. Where the determination of the CEJ was indistinct (wedge-shaped defects, fillings and crown margins), the attachment level was not recorded.

Dental examinations were conducted by five trained and calibrated dentists. For CAL measurements, interrater correlation was 0.70 and intra-rater correlations ranged between 0.67 and 0.89 . For PD measurements, examiners yielded intra-rater correlations between 0.68 and 0.88 and an inter-rater correlation of 0.72 .

\section{Caries Examination}

All examinations were conducted in an illuminated dental chair and without the use of aspiration or an air jet. Coronal caries was diagnosed visually using a periodontal probe (PCPUNC 15; Hu-Friedy, Chicago, IL, USA) to touch the tooth surface softly. Coronal caries was examined excluding third molars on a surface level according to a half-mouth design (randomly chosen left or right side). The number (DFS) and percentage (\%DFS) of decayed or filled surfaces were determined based on a maximum of 14 permanent teeth (excluding third molars) with (depending on the tooth type) 4 to 5 surfaces each, resulting in 64 surfaces being assessed in total. $^{30}$

\section{Determination of SIP Serum Concentrations}

S1P serum concentrations of the SHIP-Trend participants were measured by liquid chromatographytandem mass spectrometry (LC-MS/MS) as previously described. ${ }^{24}$ In brief, $20 \mu \mathrm{L}$ of serum were incubated with $20 \mu \mathrm{L}$ of the internal standard $(1 \mu \mathrm{mol} / \mathrm{L}$ $\left[16,17,18-{ }^{2} \mathrm{H}_{7}\right]-\mathrm{S} 1 \mathrm{P} \quad\left(\mathrm{S} 1 \mathrm{P}-\mathrm{d}_{7}\right)$, Avanti Polar Lipids). After protein precipitation with $350 \mu \mathrm{L}$ acetonitrile/ water, $80 / 20(\mathrm{vol} / \mathrm{vol})$, the extracts were subjected to reverse-phase chromatography on a $\mathrm{C} 8$ column $(2.1 \times$ $50 \mathrm{~mm}$; Zorbax SB-C8, Agilent Technologies). S1P was eluted with a binary gradient for 6 minutes (methanol/ acetonitrile/0.1\% formic acid: $2.5 / 2.5 / 95$ to $30 / 30 / 40$, $\mathrm{vol} / \mathrm{vol} / \mathrm{vol}$ ) and measured by tandem mass spectrometry (Varian L1200 MS/MS, Agilent Technologies), monitoring the $\mathrm{m} / \mathrm{z} 380$ to 264 transition of $\mathrm{S} 1 \mathrm{P}$ and the $\mathrm{m} / \mathrm{z}$ 387 to 271 transition of S1P- $\mathrm{d}_{7}$. Based on the area under the curve ratio of the S1P and S1P- $\mathrm{d}_{7}$ peaks, calibration curves (four levels of S1P: 0, 0.1, 0.3, 1, $3 \mu \mathrm{mol} / \mathrm{L}$ ) were generated to calculate absolute S1P serum concentrations. Two levels of quality controls (QCs) were included on each microtiter plate: For QC-low fetal calf serum was spiked with $0.3 \mu \mathrm{mol} / \mathrm{L} \mathrm{S1P}$ and for QC-high with $1.0 \mu \mathrm{mol} / \mathrm{L}$ S1P, respectively. For both QC levels, coefficients of variation were below $10 \%$, which was within the acceptable FDA limits for precision. 


\section{Statistical Analyses}

PD was fixed as the primary exposure and CAL was chosen as the second exposure. We pre-specified mean $\mathrm{PD}$ as the first and the percentage of sites with $\mathrm{PD} \geq 3$ or $4 \mathrm{~mm}$ (quantifying disease extent) as the second measure of the primary exposure. ${ }^{31,32}$ Accordingly, we pre-specified mean $\mathrm{CAL}$ and the percentage of sites with $\mathrm{CAL} \geq 3$ or $4 \mathrm{~mm}$ as measures of the second exposure. ${ }^{32}$ To avoid selection bias due to increased tooth loss and edentulism in elderly, we additionally performed sensitivity analyses restricting subjects to those i) with at least 12 measurement sites for according periodontal measures and ii) aged 20-59 years. As a third exposure, we defined the number of teeth, which can be seen as a proxy for periodontitis experience. The number of teeth (categorized as $0,1-9,10-19,20-27$ and 28 teeth) was only analyzed in the complete sample with full age range (20-83 years). Moreover, we evaluated the Centers for Disease Control and Prevention/American Academy of Periodontology (CDC/AAP) case definition. ${ }^{33}$

To evaluate the specificity of the association between periodontitis and S1P, two caries measures were additionally analyzed: the DFS and \%DFS indices. Both measures were only defined for dentate subjects with at least one surface being examined for caries status.

As S1P plays a crucial role in pro-inflammatory processes and periodontitis represents an inflammatory disease, we also analyzed concentrations of hs-CRP as a nonspecific marker of inflammation. Logarithmised hs-CRP levels were modelled as a restricted cubic spline with three knots.

Data were presented as mean with standard deviation (SD), median with $25 \%$ and $75 \%$ quantile or absolute frequencies (percentages). Linear regression models were fit to estimate the association between periodontitis definitions (exposure) and S1P (outcome). Linear and non-linear parameterizations of the exposure measures were tested, favoring linear forms. The adjustment set included age (as restricted cubic splines with 3 knots), gender, school education, smoking status combined with pack-years, waistto-hip-ratio, known diabetes mellitus and $\mathrm{HbAlc}$ (to assess metabolic homeostasis). Linear regression coefficients (B) with their $95 \%$ confidence intervals were presented. If the CDC/AAP case definition and the number of teeth were evaluated as the exposure, $\mathrm{P}$ values for linear trends across exposure categories were calculated. Interactions of the exposure variables with gender were non-significant $(\mathrm{p}>0.10)$. Kruskal-Wallis-tests were used to assess differences of unadjusted S1P and hs-CRP between the subgroups of CDC/AAP case definition and number of teeth. For pairwise comparisons with the respective reference group, Mann-Whitney $U$-tests were applied and $\mathrm{P}$ values were corrected for multiple testing using the Bonferroni method.

Graphics and statistical analyses were performed using R (R Development Core Team, 2008) and Stata/SE 14.2 (StataCorp, 2015).

\section{Immunofluorescence Staining of Human Gingival Tissue}

Formalin-fixed, paraffin-embedded (FFPE) tissue from a previous study was used for immunofluorescence detection of proteins involved in the S1P pathway. In this previous study, periodontal granulation tissue from periodontitis patients ( $\mathrm{PD} \geq 6 \mathrm{~mm}$ ) and control specimens from subjects undergoing tooth extraction because of caries (PD $\leq 3 \mathrm{~mm}$ ) were obtained with informed consent of the participants and ethical approval as described. ${ }^{34}$ The use of the residual FFPE tissue for the staining was additionally approved by the Ethics Committee of the University of Greifswald (BB092/13). Tissue sections ( $2-\mu \mathrm{m}$-thick) were de-paraffinized in xylene, rehydrated in a graded series of ethanol and water, and then treated with $10-\mathrm{mmol} / \mathrm{L}$ citrate buffer at $\mathrm{pH}$ 6.0. After blocking with $20 \%$ fetal calf serum, $1 \%$ saponin in phosphate-buffered saline (PBS), incubation was performed with the following primary antibodies (at $4^{\circ} \mathrm{C}$ overnight): rabbit anti-SphK1 (Abcam, Cambridge, UK; dilution 1:100) or mouse anti-SphK1 (Abgent, San Diego, CA, USA; 1:50), when co-staining was performed with rabbit anti-SPL (Abcam, Cambridge, UK; dilution 1:100), rabbit anti-SphK2 (Abcam, Cambridge, UK; dilution 1:50) and mouse anti-CD68 (Biorbyt Ltd, Cambridge, UK; dilution 1:100). After being washed with PBS, the sections were incubated for 2 hours with the respective Alexa Fluor 488 (green fluorescence)- or Alexa Fluor 568 (red fluorescence)-labelled secondary antibodies (Thermo Fisher Scientific, Waltham, MA, USA). The slides were washed and embedded using a mounting medium with 4',6-diamidino-2-phenylindole (DAPI) as a counter-stain for nuclei (Roti ${ }^{\circledR}$-Mount FluorCare DAPI, Carl Roth $\mathrm{GmbH}$, Karlsruhe, Germany). Fluorescence micrographs were taken using the confocal laser scanning microscope LSM780 (Zeiss, Jena, Germany) and a 63x/1.4 objective. 


\section{Results}

\section{Baseline Characteristics}

The study sample comprised 3371 individuals, 1739 women and 1632 men (Table 1, left part). Mean age was $50.1 \pm 14.8$ years and mean BMI was $27.9 \pm 5.1 \mathrm{~kg} / \mathrm{m}^{2}$. $27.5 \%$ reported $>10$ years of school education, while $26.8 \%$ were current smokers. Concerning cardiometabolic risks, $8.6 \%$ reported known diabetes mellitus, $10.8 \%$ the intake of statins and $8.4 \%$ of acetylsalicylic acid as platelet aggregation inhibitor. Mean S1P serum concentration was $811.7 \pm 177.1 \mathrm{nmol} / \mathrm{L}$. Unadjusted S1P did not significantly differ across categories of the CDC/AAP case definition, but was decreased in subjects with 1-9 and without teeth compared to 28 teeth $(\mathrm{P}<0.001$; Supplemental Table 1) .

Restricted to subjects with at least 12 measurement sites (Table 1, right part), 1669 women and 1562 men were included. Mean age was $49.4 \pm 14.6$ years. Remaining variables were similarly distributed compared to the total sample.

\section{Associations Between Periodontitis Parameters and SIP}

Periodontitis variables were consistently associated with S1P serum levels in fully adjusted models (Table 2, Model 2). For example, for a $1 \mathrm{~mm}$ increase in mean $\mathrm{PD}$, mean S1P increased significantly by $10.1 \mathrm{nmol} / \mathrm{L}$ (95\% CI: 0.73-19.51). For a $1 \mathrm{~mm}$ increase in mean CAL, mean S1P increased significantly by $5.14 \mathrm{nmol} / \mathrm{L}$ (95\% CI: 0.44-9.83). Results were consistent for disease extent measures. Model predicted mean S1P serum concentrations with $95 \%$ confidence bands for varying levels of mean PD and mean CAL are depicted in Figure 1.

According to the CDC/AAP classification, $48.4 \%$ had no or mild, $34.9 \%$ had moderate and $16.7 \%$ had severe periodontitis (Table 1). Fully adjusted linear regression models revealed significantly increasing S1P serum levels across different levels of the case definition $\left(\mathrm{p}_{\text {trend }}=0.03\right.$; Table 2, Model 2). In severely diseased subjects, S1P serum levels were $20.02 \mathrm{nmol} / \mathrm{L}$ higher compared to subjects with no or mild periodontitis.

With respect to the number of teeth, $16.7 \%$ had all 28 teeth (without third molars), while with $50.3 \%$ most of the subjects had 20-27 teeth. 16.4\% had 10-19 and 10.0\% had 1-9 teeth, respectively. $6.5 \%$ of the study participants were edentulous (Table 1, left part). In both models, subjects with 20-27 and 10-19 teeth showed significantly higher S1P levels compared to subjects with 28 teeth (Table 2).
For subjects with 1-9 teeth as well as edentulous subjects we did not find a consistent trend in S1P concentrations.

\section{Sensitivity Analyses of Associations Between Periodontitis Variables and SIP}

Restricting subjects to those with at least 12 measurement sites for periodontal measurements confirmed previous results (Table 3). In fully adjusted models, periodontitis variables, except mean $\mathrm{PD}$, were consistently associated with S1P (Table 3, Model 2). For the CDC/AAP case definition, S1P concentrations were on average $22.79 \mathrm{nmol} / \mathrm{L}$ higher in subjects with severe periodontitis compared to subjects with no or mild periodontitis (Table 3, Model 2).

Furthermore, to avoid selection bias due to increased tooth loss in elderly, we performed additional sensitivity analyses for linear regression models restricting subjects to those aged 20-59 years (Supplemental Table 2). In accordance with previous results, periodontitis variables were consistently associated with S1P concentrations with regard to the direction of effect estimates, albeit some associations were no longer significant after full adjustment.

\section{Associations Between Caries Variables and SIP}

In order to verify the specificity of the associations between periodontitis variables and S1P serum concentrations, we assessed associations with two caries variables. Mean DFS was $16.6 \pm 10.3$; mean \%DFS was $38.1 \pm 25.3 \%$ (Table 1). Fully adjusted linear regression models showed no significant associations with S1P serum concentrations (Supplemental Table 3, Model 2).

\section{Associations Between C-Reactive Protein and SIP}

Mean hs-CRP concentration was $2.5 \pm 5.0 \mathrm{mg} / \mathrm{L}$ (Table 1). Subjects with moderate and severe periodontitis showed elevated hs-CRP levels compared to no or mild periodontitis ( $\mathrm{P}<0.001$; Supplemental Table 1). Moreover, hs-CRP concentrations increased with a decreasing number of teeth ( $<0.001$; Supplemental Table 1). In a fully adjusted linear regression model, S1P serum concentrations significantly increased with increasing hs-CRP levels (Figure 2).

\section{Expression of SIP-Metabolizing Enzymes in Inflamed Human Gingival Tissue}

We investigated the expression of SphK1 and SphK2 as well as of SPL by immunofluorescence staining in FFPE 
Table I Baseline Characteristics of Study Subjects; Study of Health in Pomerania (SHIP-Trend-0; 2008-20I2)

\begin{tabular}{|c|c|c|c|c|}
\hline & $\mathbf{N}$ & $\begin{array}{l}\text { Participants } \\
\text { Aged 20-83 } \\
\text { Years }\end{array}$ & $\mathbf{N}$ & $\begin{array}{c}\text { Participants Aged 20-83 Years with } \geq 12 \\
\text { Periodontal Measurement Sites }\end{array}$ \\
\hline Age, years & 3371 & $50.1 \pm 14.8$ & 3231 & $49.4 \pm 14.6$ \\
\hline Male gender & 3371 & $1632(48.4 \%)$ & 3231 & 1562 (48.3\%) \\
\hline $\begin{array}{l}\text { School education } \\
<10 \text { years } \\
10 \text { years } \\
>10 \text { years }\end{array}$ & 3371 & $\begin{array}{l}620(18.4 \%) \\
1823(54.1 \%) \\
928(27.5 \%)\end{array}$ & 3231 & $\begin{array}{l}555(17.2 \%) \\
1767(54.7 \%) \\
909(28.1 \%)\end{array}$ \\
\hline $\begin{array}{l}\text { Smoking status } \\
\text { Never } \\
\text { Former with }<20 \text { pack years } \\
\text { Former with } \geq 20 \text { pack years } \\
\text { Current with }<20 \text { pack years } \\
\text { Current with } \geq 20 \text { pack years }\end{array}$ & 3371 & $\begin{array}{l}1243(36.9 \%) \\
990(29.4 \%) \\
235(7.0 \%) \\
617(18.3 \%) \\
286(8.5 \%)\end{array}$ & 3231 & $\begin{array}{l}1196(37.0 \%) \\
949(29.4 \%) \\
216(6.7 \%) \\
613(19.0 \%) \\
257(7.9 \%)\end{array}$ \\
\hline Known diabetes mellitus, yes & 3371 & $290(8.6 \%)$ & 3231 & $250(7.7 \%)$ \\
\hline $\mathrm{HbAlc} \%$ & 3371 & $5.3 \pm 0.8$ & 3231 & $5.3 \pm 0.8$ \\
\hline Body mass index, $\mathrm{kg} / \mathrm{m}^{2}$ & 3371 & $27.9 \pm 5.1$ & 3231 & $27.7 \pm 5.0$ \\
\hline Waist-to-hip-ratio & 3371 & $0.88 \pm 0.09$ & 3231 & $0.88 \pm 0.09$ \\
\hline $\begin{array}{l}\text { Medication, yes } \\
\text { Statins } \\
\text { Acetylsalicylic acid as platelet } \\
\text { aggregation inhibitor } \\
\text { Cortisone } \\
\text { Systemic antibiotics }\end{array}$ & 3371 & $\begin{array}{l}364(10.8 \%) \\
283(8.4 \%) \\
25(0.7 \%) \\
36(1.1 \%)\end{array}$ & 3231 & $\begin{array}{l}314(9.7 \%) \\
242(7.5 \%) \\
20(0.6 \%) \\
34(1.1 \%)\end{array}$ \\
\hline Mean PD, mm & 3371 & $\begin{array}{l}2.6 \pm 0.7 \\
2.4(2.1 ; 2.8)\end{array}$ & 3231 & $\begin{array}{c}2.6 \pm 0.7 \\
2.4(2.1 ; 2.8)\end{array}$ \\
\hline Percentage of sites with PD $3+\mathrm{mm}$, \% & 3371 & $\begin{array}{l}43.0 \pm 23.4 \\
40.0(25.0 ; 58.3)\end{array}$ & 3231 & $\begin{array}{c}42.2 \pm 22.7 \\
39.6(25.0 ; 57.1)\end{array}$ \\
\hline Percentage of sites with PD 4+mm, \% & 3371 & $\begin{array}{l}14.4 \pm 19.3 \\
6.3(0 ; 20.0)\end{array}$ & 3231 & $\begin{array}{l}13.8 \pm 18.6 \\
6.3(0 ; 19.2)\end{array}$ \\
\hline Mean CAL, mm & 3198 & $\begin{array}{l}2.5 \pm 1.7 \\
2.1(1.6 ; 3.3)\end{array}$ & 2983 & $\begin{array}{c}2.3 \pm 1.5 \\
1.9(1.2 ; 3.1)\end{array}$ \\
\hline $\begin{array}{l}\text { Percentage of sites with CAL } 3+\mathrm{mm} \text {, } \\
\%\end{array}$ & 3198 & $\begin{array}{l}39.8 \pm 34.7 \\
31.3(7.1 ; 70.0)\end{array}$ & 2983 & $\begin{array}{c}36.7 \pm 33.1 \\
27.5(5.8 ; 64.3)\end{array}$ \\
\hline $\begin{array}{l}\text { Percentage of sites with CAL } 4+m m \text {, } \\
\%\end{array}$ & 3198 & $\begin{array}{l}24.7 \pm 30.9 \\
9.4(0 ; 40.4)\end{array}$ & 2983 & $\begin{array}{l}21.6 \pm 27.9 \\
8.1(0 ; 33.3)\end{array}$ \\
\hline $\begin{array}{l}\text { CDC/AAP case definition } \\
\text { No or mild } \\
\text { Moderate } \\
\text { Severe }\end{array}$ & 3120 & $\begin{array}{l}15||(48.4 \%) \\
1088(34.9 \%) \\
52 \mid(\mid 6.7 \%)\end{array}$ & 2983 & $\begin{array}{l}1476(49.5 \%) \\
1027(34.4 \%) \\
480(16.1 \%)\end{array}$ \\
\hline
\end{tabular}

(Continued) 
Table I (Continued).

\begin{tabular}{|c|c|c|c|c|}
\hline & $\mathbf{N}$ & $\begin{array}{c}\text { Participants } \\
\text { Aged 20-83 } \\
\text { Years }\end{array}$ & $\mathbf{N}$ & $\begin{array}{c}\text { Participants Aged } 20-83 \text { Years with } \geq 12 \\
\text { Periodontal Measurement Sites }\end{array}$ \\
\hline Number of teeth & 4042 & & - & \\
\hline 28 & & $677(16.8 \%)$ & & - \\
\hline $20-27$ & & $2032(50.3 \%)$ & & - \\
\hline $10-19$ & & $664(16.4 \%)$ & & - \\
\hline $1-9$ & & $405(10.0 \%)$ & & - \\
\hline 0 & & $264(6.5 \%)$ & & - \\
\hline Number of decayed or filled surfaces & 3421 & $\begin{array}{l}16.6 \pm 10.3 \\
16.0(9.0 ; 24.0)\end{array}$ & - & - \\
\hline $\begin{array}{l}\text { Percentage of decayed or filled } \\
\text { surfaces, } \%\end{array}$ & 3421 & $\begin{array}{l}38.1 \pm 25.3 \\
34.4(18.6 ; 53.1)\end{array}$ & - & - \\
\hline Sphingosine-I-phosphate, nmol/L & 3371 & $\begin{array}{l}811.7 \pm 177.1 \\
800.1(684.3 ; 919.8)\end{array}$ & 3231 & $\begin{array}{c}813.6 \pm 175.8 \\
801.7(686.7 ; 920.3)\end{array}$ \\
\hline $\begin{array}{l}\text { High-sensitivity C-reactive } \\
\text { protein, } \mathrm{mg} / \mathrm{L}\end{array}$ & 3198 & $\begin{array}{l}2.5 \pm 5.0 \\
1.3(0.7 ; 2.8)\end{array}$ & 3066 & $\begin{array}{c}2.5 \pm 5.0 \\
\text { I. } 2(0.7 ; 2.7)\end{array}$ \\
\hline $\begin{array}{l}\text { High-sensitivity C-reactive protein } \\
\qquad \begin{array}{l}\leq 2 \mathrm{mg} / \mathrm{L} \\
>2 \mathrm{mg} / \mathrm{L} \text { and } \leq 3 \mathrm{mg} / \mathrm{L} \\
>3 \mathrm{mg} / \mathrm{L}\end{array}\end{array}$ & 3283 & $\begin{array}{l}2180(66.4 \%) \\
355(10.8 \%) \\
748(22.8 \%)\end{array}$ & 3150 & $\begin{array}{c}2124(67.4 \%) \\
339(10.8 \%) \\
687(21.8 \%)\end{array}$ \\
\hline
\end{tabular}

Notes: Data are presented as mean \pm standard deviation (SD), median (25\%; $75 \%$ quantile) or absolute frequencies (percentages). Medication intake was defined for regularly taken statins (ATC code CIOAA), corticosteroids (ATC codes H02A and H02B), acetylsalicylic acid as platelet aggregation inhibitor (B0IAC06) or systemic antibiotics (ATC code J0I).

Abbreviations: PD, probing depth; CAL, clinical attachment loss; CDC/AAP, Centers for Disease Control and Prevention/American Academy of Periodontology.

tissue from periodontitis patients and control specimens (Figure 3 and Supplemental Figure 2). Staining of SphK1 indicated higher expression levels of this S1P-generating enzyme in the inflamed gingival tissue (inflamed gingival tissue: Figure 3D-F vs normal gingival tissue: Figure 3AC). Intensive staining of SphK1 was especially observed in the gingival epithelium of periodontitis samples and in CD68-positive immune cells (Supplemental Figure 2A and B, left panels). SphK2 was also detected in the epithelium. However, no significant difference was observed between normal and inflamed tissue for this isoform (Supplemental Figure 2A, right panels). Staining of the S1P-degrading enzyme SPL revealed a diffuse expression in the sections of inflamed gingival tissue (Figure 3F), whereas in sections of normal gingival tissue we observed mainly a blood vessel-associated expression pattern (Figure 3C).

\section{Discussion}

We identified a potential link between periodontitis and S1P serum concentrations using data from the population- based SHIP-Trend cohort. Specifically, S1P serum concentrations were significantly increased in subjects with both moderate and severe periodontitis. Moreover, S1P serum concentrations were significantly associated with different periodontitis variables quantifying either severity (mean) or extent (percentage of affected sites) of current (PD) or lifetime-accumulated periodontal disease (CAL). In contrast, no significant association of the inflammatory mediator S1P was seen with the DFS or the \%DFS, pointing towards a specific role of S1P primarily in inflammatory disease conditions such as periodontitis rather than caries, which is primarily driven by demineralization of enamel and dentin by acids, produced by oral bacteria.

Furthermore, in inflamed compared to normal human gingival tissue, we detected higher expression levels of the S1P-generating enzyme SphK1 in CD68-positive macrophages and related immune cells (Figure 3 and Supplemental Figure 2), which may cause locally elevated S1P concentrations. Intriguingly, the SHIP-Trend data indicated that periodontitis was also associated with increased circulating S1P levels. Whether S1P that is 
Table 2 Results from Linear Regression Models Analyzing the Association Between Periodontitis Variables and SphingosineI-Phosphate Serum Levels (Continuously Modelled) in All Subjects (Aged 20-83 Years)

\begin{tabular}{|c|c|c|c|c|c|}
\hline \multirow[b]{2}{*}{ Periodontitis variables } & \multirow[b]{2}{*}{$\mathrm{N}$} & \multicolumn{2}{|c|}{ Model I, Adjusted for Age and Gender } & \multicolumn{2}{|c|}{ Model 2, Fully Adjusted } \\
\hline & & B (95\% Cl) & $P$ value & $\mathrm{B}(95 \% \mathrm{Cl})$ & $P$ value \\
\hline Mean PD, mm & 3371 & $12.89(3.83 ; 21.95)$ & 0.005 & $10.12(0.73 ; 19.51)$ & 0.04 \\
\hline Percentage of sites with PD $3+\mathrm{mm}, 10 \%$ & 3371 & $4.52(1.83 ; 7.23)$ & 0.001 & $3.83(1.02 ; 6.64)$ & 0.008 \\
\hline Percentage of sites with PD $4+\mathrm{mm}, 10 \%$ & 3371 & $4.94(1.72 ; 8.16)$ & 0.003 & $3.83(0.48 ; 7.19)$ & 0.03 \\
\hline Mean CAL, mm & 3198 & $6.72(2.20 ; 11.24)$ & 0.004 & $5.14(0.44 ; 9.83)$ & 0.03 \\
\hline Percentage of sites with CAL $3+\mathrm{mm}, 10 \%$ & 3198 & $4.13(1.84 ; 6.42)$ & $<0.001$ & $3.38(1.00 ; 5.76)$ & 0.005 \\
\hline Percentage of sites with CAL $4+\mathrm{mm}, 10 \%$ & 3198 & $3.27(0.84 ; 5.7 I)$ & 0.008 & $2.68(0.15 ; 5.21)$ & 0.04 \\
\hline CDC/AAP definition & 3120 & & & & \\
\hline No or mild & 1511 & 0.00 (Ref.) & & 0.00 (Ref.) & \\
\hline Moderate & 1088 & I8.8I (3.74; 33.88) & 0.01 & $14.75(-0.42 ; 29.92)$ & 0.06 \\
\hline Severe & 521 & $\begin{array}{l}25.50(6.03 ; 44.97) \\
P_{\text {trend }}=0.006\end{array}$ & 0.01 & $\begin{array}{c}20.02(0.10 ; 39.94) \\
P_{\text {trend }}=0.03\end{array}$ & 0.049 \\
\hline Number of teeth & 4042 & & & & \\
\hline 28 & 677 & 0.00 (Ref.) & & 0.00 (Ref.) & \\
\hline $20-27$ & 2032 & 21.16 (3.91; 38.40) & 0.02 & $20.56(3.35 ; 37.78)$ & 0.02 \\
\hline $10-19$ & 664 & $25.77(3.16 ; 48.37)$ & 0.03 & $22.5 I(-0.31 ; 45.34)$ & 0.05 \\
\hline $1-9$ & 405 & |3.64 (-12.11; 39.39) & 0.30 & $12.36(-13.92 ; 38.64)$ & 0.40 \\
\hline 0 & 264 & $\begin{array}{c}24.56(-4.42 ; 53.55) \\
P_{\text {trend }}=0.32\end{array}$ & 0.10 & $\begin{array}{l}20.10(-9.88 ; 50.09) \\
\quad P_{\text {trend }}=0.51\end{array}$ & 0.20 \\
\hline $\begin{array}{l}\text { Number of teeth } \\
\text { (only subjects with PD assessments) }\end{array}$ & 3370 & & & & \\
\hline 28 & 630 & 0.00 (Ref.) & & 0.00 (Ref.) & \\
\hline $20-27$ & 1850 & $17.93(-0.32 ; 36.17)$ & 0.05 & $16.98(-1.21 ; 35.17)$ & 0.07 \\
\hline $10-19$ & 583 & $25.82(1.74 ; 49.89)$ & 0.04 & $21.34(-2.96 ; 45.63)$ & 0.09 \\
\hline $1-9$ & 307 & $\begin{array}{c}12.44(-16.09 ; 40.96) \\
P_{\text {trend }}=0.29\end{array}$ & 0.40 & $\begin{array}{c}12.02(-17.04 ; 41.08) \\
P_{\text {trend }}=0.38\end{array}$ & 0.40 \\
\hline
\end{tabular}

Notes: Model 2 was adjusted for age (cubic splines with 3 knots), gender, school education, smoking status combined with pack-years, waist-to-hip-ratio, known diabetes mellitus and $\mathrm{HbAlc}$.

Abbreviations: PD, probing depth; CAL, clinical attachment loss; CDC/AAP, Centers for Disease Control and Prevention/American Academy of Periodontology; N, number; B, linear regression coefficient; $\mathrm{Cl}$, confidence interval.

locally generated by immune cells directly contributes to the elevated serum levels in subjects with periodontitis is uncertain. An alternative explanation of the observed association of serum S1P with periodontitis markers is that periodontitis is generally associated with low-grade systemic inflammation, ie, increased levels of white blood cells, fibrinogen and CRP, ${ }^{7,8,35-37}$ which may in turn result in an elevated systemic S1P release by platelets, white blood cells, and endothelial cells as the main cellular sources. ${ }^{38,39}$ This interpretation of our data is in agreement with the known property of S1P as a major inflammatory mediator and immunomodulator ${ }^{40,41}$ and is supported by the observed significant association of serum S1P with hs-
CRP levels (Figure 2). In addition, other authors have established a molecular link between S1P and CRP during the invasive process of breast epithelial cells. ${ }^{42}$ Nevertheless, the intriguing positive association between S1P and CRP that we found in our analyses could not be observed in previous studies focusing on other chronic inflammatory diseases. ${ }^{43,44}$ During processes of severe inflammation such as sepsis, however, S1P was inversely correlated with parameters of disease severity including $\mathrm{CRP}^{23}$ which may point towards a critical role of S1P in low-grade versus detrimental loss-of-function effects during high-grade inflammation. Overall, the here observed increase of serum S1P in subjects with periodontitis could 
A

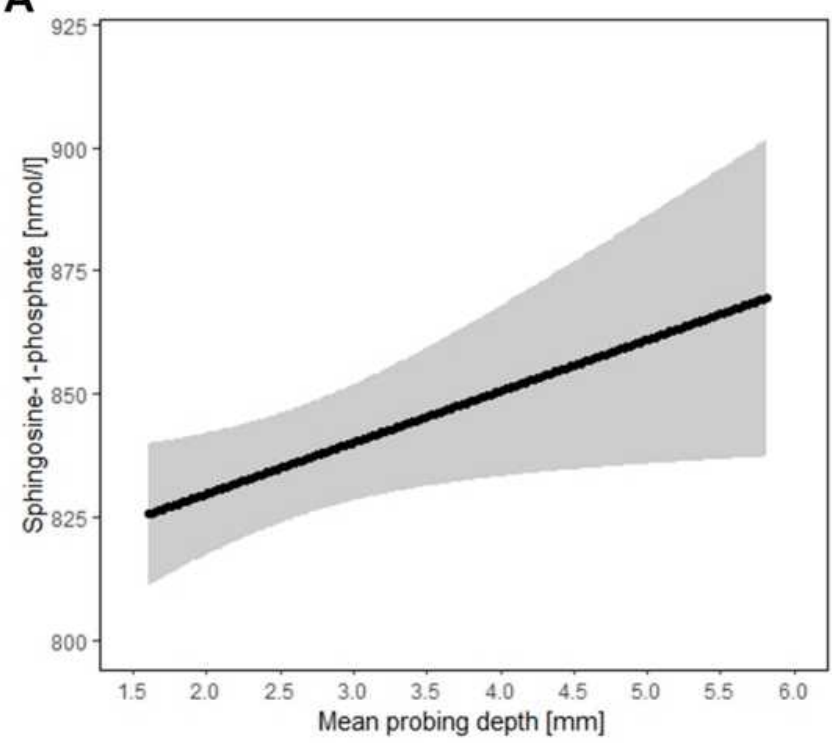

B

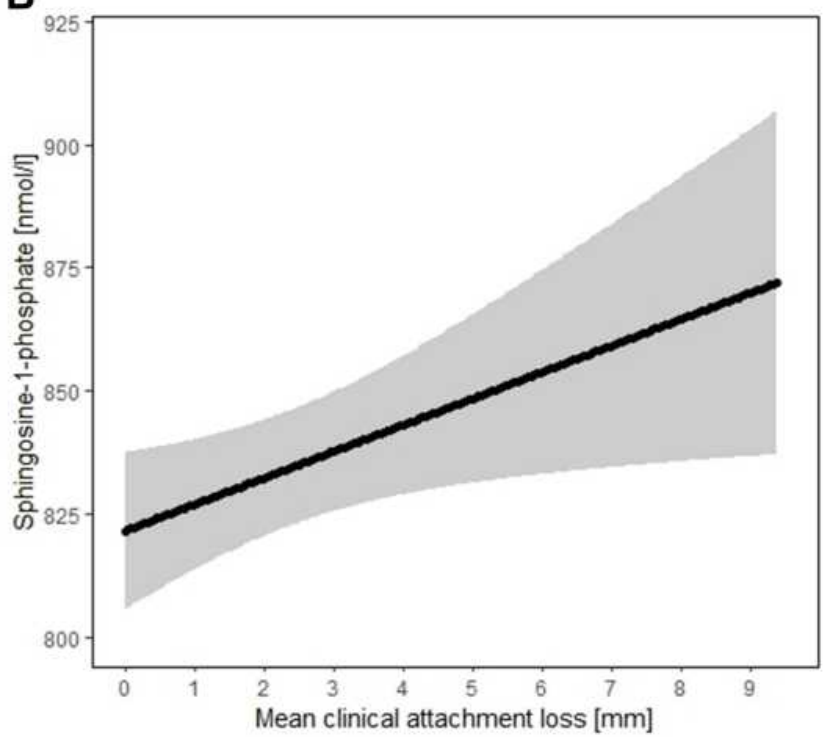

Figure I Model predicted mean (with 95\% confidence bands) of sphingosine-I-phosphate serum concentrations for varying levels of (A) mean probing depth and (B) mean clinical attachment loss.

be most presumably attributed to both processes described above.

In addition to the obtained periodontitis parameters, the number of teeth evaluated in our study was also significantly associated with circulating serum S1P levels (Table 2). At least, this was the case for individuals with a number of 20-27 teeth in both models and for individuals with 10-19 teeth in Model 1 and borderline significant $(\mathrm{p}=0.053)$ in Model 2 (Table 2). In comparison, both the group with less than 9 teeth and the edentulous study participants showed no significant association with S1P. This may in part be attributed to unknown confounding

Table 3 Results from Linear Regression Models Analyzing the Association Between Periodontitis Variables and SphingosineI-Phosphate Serum Levels (Continuously Modelled) in Subjects Aged 20-83 Years with at Least 12 Measurement Sites for Assessments of Probing Depth or Clinical Attachment Loss

\begin{tabular}{|c|c|c|c|c|c|}
\hline \multirow[b]{2}{*}{ Periodontitis variables } & \multirow[b]{2}{*}{$\mathrm{N}$} & \multicolumn{2}{|c|}{ Model I, Adjusted for Age and Gender } & \multicolumn{2}{|c|}{ Model 2, Fully Adjusted } \\
\hline & & $\mathrm{B}(95 \% \mathrm{Cl})$ & $P$ value & $\mathrm{B}(95 \% \mathrm{Cl})$ & $P$ value \\
\hline Mean PD, mm & 3231 & $12.61(3.06 ; 22.17)$ & 0.01 & $9.30(-0.63 ; 19.23)$ & 0.07 \\
\hline Percentage of sites with PD $3+\mathrm{mm}, 10 \%$ & 3231 & $4.43(1.61 ; 7.24)$ & 0.002 & $3.5 \mathrm{I}(0.57 ; 6.45)$ & 0.02 \\
\hline Percentage of sites with PD $4+\mathrm{mm}, 10 \%$ & 3231 & $5.23(1.82 ; 8.63)$ & 0.003 & $3.96(0.40 ; 7.5 I)$ & 0.03 \\
\hline Mean CAL, mm & 2983 & $8.13(2.84 ; 13.42)$ & 0.003 & $6.07(0.59 ; 11.55)$ & 0.03 \\
\hline Percentage of sites with CAL $3+\mathrm{mm}, 10 \%$ & 2983 & $4.75(2.31 ; 7.20)$ & $<0.001$ & $3.82(1.28 ; 6.35)$ & 0.003 \\
\hline Percentage of sites with CAL $4+\mathrm{mm}, 10 \%$ & 2983 & $4.02(1.27 ; 6.77)$ & 0.03 & $3.16(0.31 ; 6.01)$ & 0.004 \\
\hline CDC/AAP case definition & 2983 & & & & \\
\hline No or mild & 1476 & 0.00 (Ref.) & & 0.00 (Ref.) & \\
\hline Moderate & 1027 & $20.02(4.63 ; 35.40)$ & 0.01 & I5.22(-0.27; 30.7I) & 0.054 \\
\hline Severe & 480 & $\begin{array}{c}29.22(9.16 ; 49.27) \\
P_{\text {trend }}=0.002\end{array}$ & 0.004 & $\begin{array}{c}22.79(2.24 ; 43.35) \\
P_{\text {trend }}=0.02\end{array}$ & 0.03 \\
\hline
\end{tabular}

Notes: Model 2 was adjusted for age (cubic splines with 3 knots), gender, school education, smoking status combined with pack-years, waist-to-hip-ratio, known diabetes mellitus and HbAIc. PD, probing depth.

Abbreviations: CAL, clinical attachment loss; CDC/AAP, Centers for Disease Control and Prevention/American Academy of Periodontology; N, number; B, linear regression coefficient; $\mathrm{Cl}$, confidence interval. 


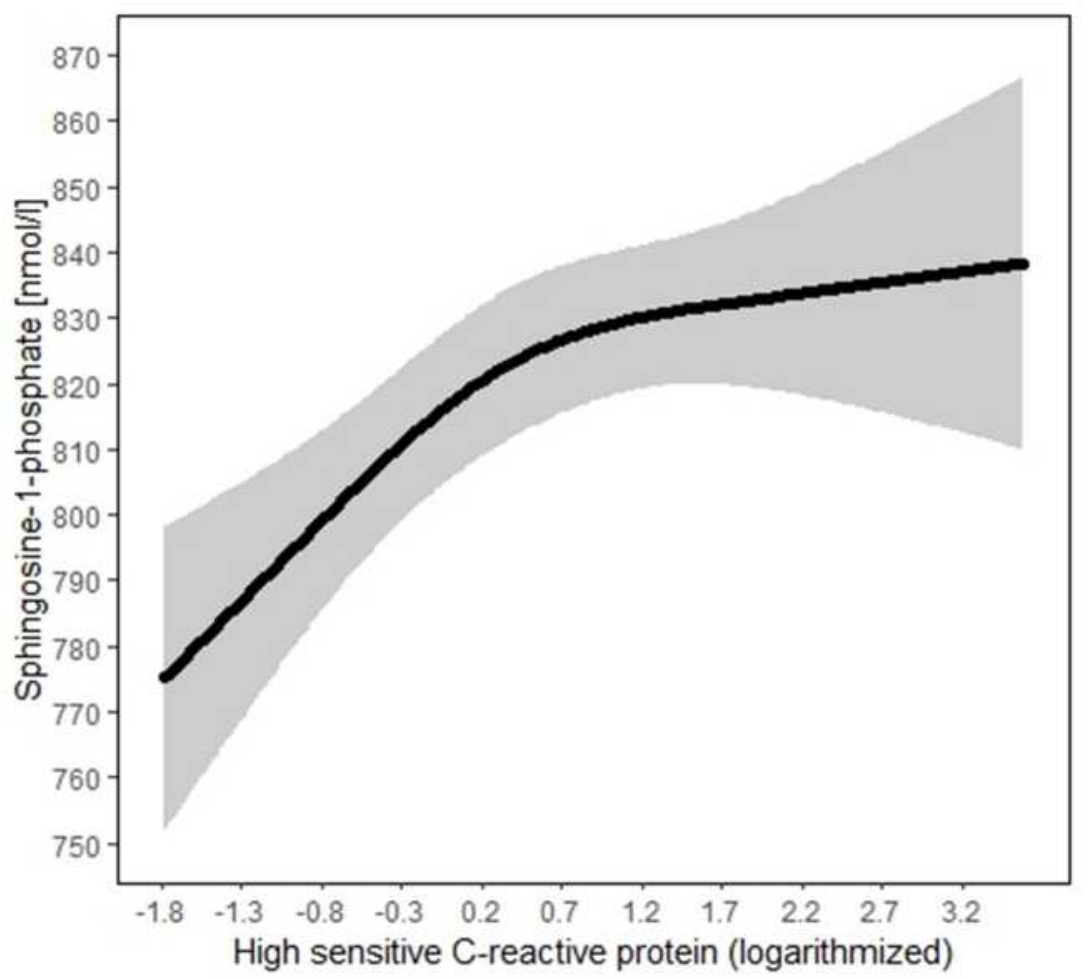

Figure 2 Model predicted mean (with 95\% confidence bands) of sphingosine-I-phosphate serum concentrations for varying levels of high-sensitivity C-reactive protein (logarithmised). Estimates for effects of logarithmised CRP levels on SIP were B=24.5 (standard error 6.7, $p<0.001$ ) for the first spline and B=-15.4 (standard error 7.9, $\mathrm{P}=0.053$ ) for the second spline according to the fully adjusted linear regression model.

factors in elderly individuals which have not been considered, but also to the lower number to individuals in these study groups. Nevertheless, the striking association of serum S1P levels with markers of periodontitis severity and extent in a population-based cohort study has not been reported to date and may point to a potential role of elevated serum S1P levels as an indicative marker for the severity of periodontitis and possibly tooth loss.

Numerous studies have addressed the key role of $\mathrm{S} 1 \mathrm{P}$ as an inflammatory mediator and potential therapeutic target in several pathologies such as cardiovascular, neurological and tumor diseases. ${ }^{14,15}$ In addition, $\mathrm{S} 1 \mathrm{P}$ has emerged as a prognostic biomarker, eg, for cardiovascular disease $^{22}$ and sepsis. ${ }^{23}$ S1P does not only locally interlink blood coagulation and vessel wall inflammation within atherosclerotic lesions, ${ }^{41,45}$ but also mediates cellular processes as $\mathrm{S} 1 \mathrm{P}$ regulates both the homing of immune cells to lymphoid organs and their egress into blood and lymph. ${ }^{46-48}$ Tissue concentrations of S1P increase early during acute immune or inflammatory responses and decrease as inflammation resolves. $^{39}$ Correspondingly, deficiency of the S1Pdegrading enzyme SPL causes a pro-inflammatory response. ${ }^{38}$ Moreover, S1P levels are elevated in different inflammatory disorders and autoimmune diseases, eg, in patients with multiple sclerosis (MS), ${ }^{49}$ Crohn's disease and ulcerative colitis. ${ }^{50-52}$ Specifically, increased S1P serum concentrations were observed in inflammatory bone and joint-related diseases, ie, spondyloarthritis and rheumatoid arthritis. ${ }^{43,53}$ Here, both elevated S1P concentrations and higher S1PR1 expression were described in the synovial fluid, ${ }^{53,54}$ whereas in leukocytes the S1PR1 expression level was decreased. ${ }^{44}$ However, the absolute S1P concentrations cannot be directly compared to the values observed in our investigation due to the different quantitation methods and notably lower sample numbers in these studies.

In periodontitis, S1P has been implicated in inducing pro-inflammatory cytokine production, eg, of interferon beta (IFN-beta), interleukin 6 (IL-6) and interleukin 8 (IL-8), in primary human gingival epithelial cells, which is mediated via S1PR1 and S1PR3. ${ }^{55,56}$ In SphK1-deficient mice periodontal inflammation and alveolar bone loss were attenuated after injection of A. actino-mycetemcomitans into the periodontal tissue, whereas the wildtype littermates showed increased SphK1 expression. ${ }^{57}$ 

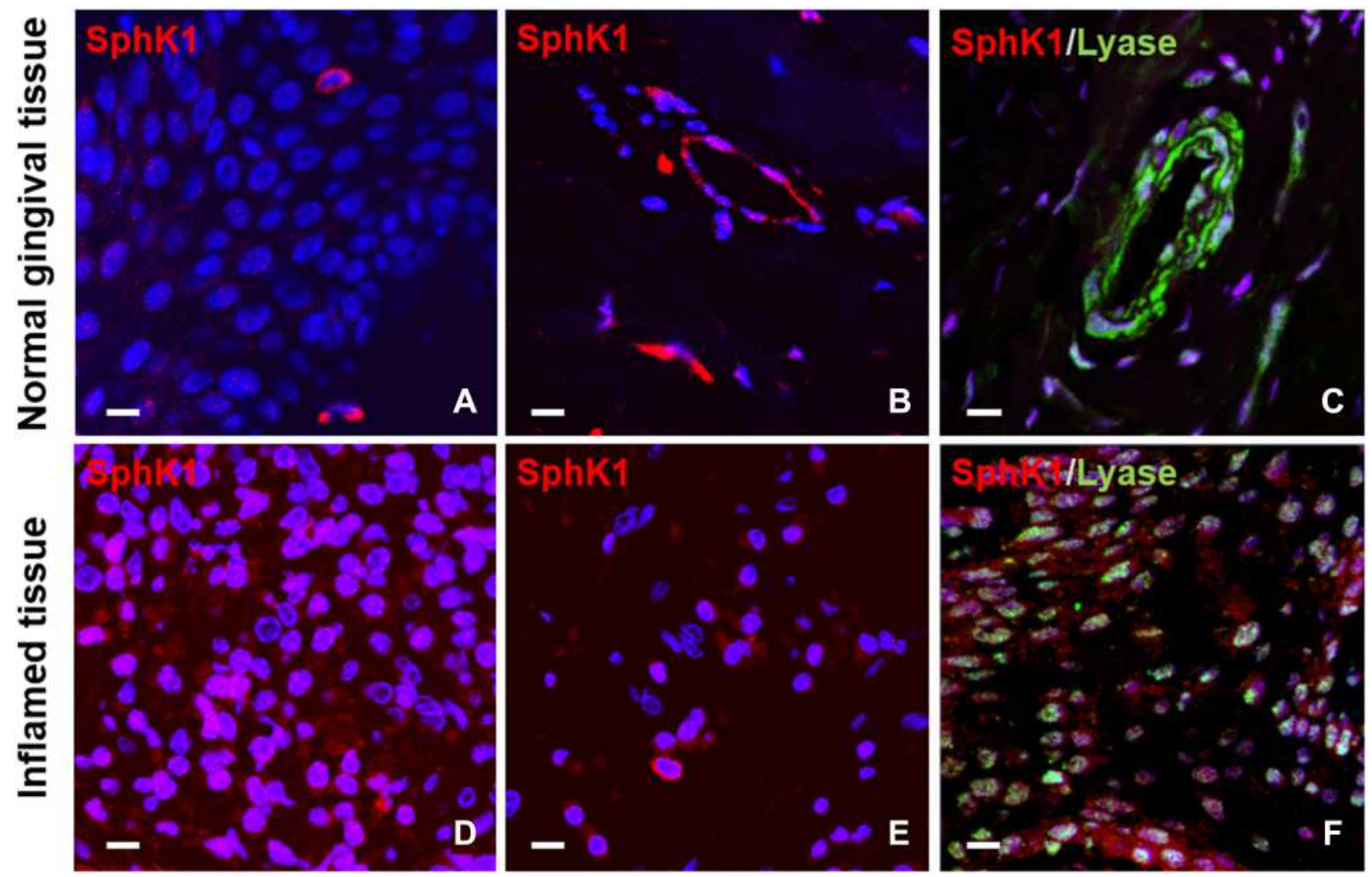

Figure 3 Representative immunofluorescence staining of human gingival tissue (A-F). (A-C) represent paraffin-embedded sections of normal gingival tissue, whereas (DF) show paraffin-embedded sections of inflamed gingival tissue. Both DAPI staining of nuclei (blue) and staining of the sphingosine-I-phosphate (SIP)-generating enzyme sphingosine kinase I (SphKI; red) were performed for all sections (A-F). Staining of the SIP-degrading enzyme sphingosine-I-phosphate lyase (Lyase; green) was conducted in section C+F. Fluorescence micrographs were taken using a laser scanning microscope (Zeiss LSM780) and a $63 \mathrm{x} / \mathrm{I} .4 \mathrm{objective}(\mathrm{bar}=10 \mu \mathrm{m})$.

Accordingly, treatment with the functional S1PR1 antagonist Fingolimod reduced the formation of pro-inflammatory cytokines, eg, interleukin $1 \beta$ (IL-1 $\beta$ ), IL-6 and tumor necrosis factor $\alpha(\mathrm{TNF}-\alpha)$ in murine bone marrow-derived monocytes and macrophages after stimulation with A. actinomycetemcomitans. ${ }^{58}$ Moreover, Fingolimod promoted re-migration of osteoclast precursors from the alveolar bone surface into blood vessels, thereby reducing osteoclast formation in periodontal lesions of rats with ligature-induced periodontitis. ${ }^{59}$ The data described herein support the hypothesis that $\mathrm{S} 1 \mathrm{P}$ and its signaling system are linked to the pathogenesis of periodontitis.

Besides its involvement as a mediator in pathological processes, modifying the S1P system or its signaling components such as the S1P receptors is also of therapeutic potential. The S1P receptor modulator Fingolimod and comparable compounds have been in clinical use for patients with MS for several years ${ }^{60}$ and a number of additional clinical applications in S1P-driven inflammatory conditions have been proposed. ${ }^{61}$ A particular promising clinical application of modifying S1P signaling could be the targeting of bone-related diseases. ${ }^{27,62}$ Recent data from our group indicated S1P-based drugs as a promising therapeutic avenue for the treatment of osteoporotic diseases. ${ }^{27}$ Intriguingly, S1P was associated with bone formation markers, but not with resorption markers in the SHIPTrend cohort. ${ }^{27}$ Inhibition of the S1P lyase, which resulted in attenuated S1P degradation and increased S1P availability, was associated with increased bone formation in experimental in-vivo models. ${ }^{27}$ Contrariwise, increased S1P plasma levels predicted osteoporosis-related fractures in postmenopausal women. ${ }^{63}$ In light of the results described here, it seems reasonable to assume that modification of local S1P availability or signaling, ie, by applying S1P receptor inhibitors or modulators such as Fingolimod, might modulate inflammatory disease burden and possibly also local bone destruction in periodontitis. Our finding of a markedly increased expression of SphK1 during 
periodontitis points towards a potential therapeutic suitability of compounds such as Fingolimod, which besides the functional antagonism of S1PR1 is an inhibitor of SphK1 activity. ${ }^{64-66}$ The clinical feasibility of a local application of S1P-based drugs as slow release device, oral rinse or tooth paste in patients with periodontitis must be addressed in future studies.

\section{Conclusion}

Taken together, our study is the first to report an intriguingly significant association of various parameters characterizing periodontitis severity as well as extent and serum levels of the inflammatory lipid mediator S1P. In addition, a prominent expression of the S1P-generating enzyme SphK1 was observed in gingival tissue samples from periodontitis patients. Our data point towards a key role of S1P during periodontitis. Modulation of local S1P levels or its signaling properties may represent a potential future therapeutic strategy to prevent or to retard periodontitis progression and possibly reduce periodontitis-related tooth loss.

\section{Acknowledgments}

This work was funded by a grant from the DZHK (Deutsches Zentrum für Herz-Kreislauf-Forschung e.V., Grant $81 \times 2400111$ ). The SHIP-TREND study is part of the Community Medicine Research net of the University of Greifswald, Germany, which is funded by the Federal Ministry of Education and Research (Grants 01ZZ9603, 01ZZ0103, and 01ZZ0403), the Ministry of Cultural Affairs as well as the Social Ministry of the Federal State of Mecklenburg-West Pomerania. We acknowledge support for the Article Processing Charge from the DFG (German Research Foundation, 393148499) and the Open Access Publication Fund of the University of Greifswald.

\section{Disclosure}

Prof. Dr. Matthias Nauck reports grants from Federal Ministry of Education and Research Germany, the Ministry of Cultural Affairs, the Social Ministry of the Federal State of Mecklenburg-West Pomerania, during the conduct of the study; grants from Federal Ministry of Education and Research, Germany, European Union Interreg IVa, personal fees from German Medical Association, German Centre for Cardiovascular Research (GCCR), National Cohort, outside the submitted work. The authors report no other conflicts of interest in this work.

\section{References}

1. Kumar V, Abbas AK, Aster JC. Robbins \& Cotran Pathologic Basis of Disease. 10th ed. International edition; 2021

2. Kassebaum NJ, Bernabé E, Dahiya M, Bhandari B, Murray CJL, Marcenes W. Global burden of severe periodontitis in 1990-2010: a systematic review and meta-regression. J Dent Res. 2014;93 (11):1045-1053. doi:10.1177/0022034514552491

3. Hoffmann T. Krankheits- und Versorgungsprävalenzen bei Jüngeren Erwachsenen (35-bis 44-Jährige). In: Jordan AR, Micheelis W, editors. Fünfte Deutsche Mundgesundheitsstudie (DMS V). Köln: Deutscher Ärzteverlag (DÄV); 2016:312-334.

4. Kocher THB. Krankheits- und Versorgungsprävalenzen bei Jüngeren Senioren (65-bis 74-Jährige). In: Jordan AR, Micheelis W, editors. Fünfte Deutsche Mundgesundheitsstudie (DMS V). Köln: Deutscher Ärzteverlag (DÄV); 2016:396-415.

5. Kocher T, Holtfreter B. Editorial: Is the prevalence of periodontitis declining or not? Oral Health Prev Dent. 2017;15(6):501-502.

6. Schützhold S, Kocher T, Biffar R, et al. Changes in prevalence of periodontitis in two German population-based studies. $J$ Clin Periodontol. 2015;42(2):121-130. doi:10.1111/jcpe.12352

7. Hajishengallis G. Periodontitis: from microbial immune subversion to systemic inflammation. Nat Rev Immunol. 2015;15(1):30-44. doi: $10.1038 /$ nri3785

8. Schenkein HA, Loos BG. Inflammatory mechanisms linking periodontal diseases to cardiovascular diseases. J Clin Periodontol. 2013;40 (Suppl 14):S51-69. doi:10.1111/jcpe.12060

9. Chistiakov DA, Orekhov AN, Bobryshev YV. Links between atherosclerotic and periodontal disease. Exp Mol Pathol. 2016;100(1):220-235.

10. Holtfreter B, Empen K, Gläser S, et al. Periodontitis is associated with endothelial dysfunction in a general population: a cross-sectional study. PLoS One. 2013;8(12):e84603. doi:10.1371/ journal.pone. 0084603

11. Yu Y-H, Chasman DI, Buring JE, Rose L, Ridker PM. Cardiovascular risks associated with incident and prevalent periodontal disease. J Clin Periodontol. 2015;42(1):21-28. doi:10.1111/jcpe.12335

12. Carrizales-Sepúlveda EF, Ordaz-Farías A, Vera-Pineda R, FloresRamírez R. Periodontal disease, systemic inflammation and the risk of cardiovascular disease. Heart Lung Circ. 2018;27(11):1327-1334. doi:10.1016/j.hlc.2018.05.102

13. Tomás I, Diz P, Tobías A, Scully C, Donos N. Periodontal health status and bacteraemia from daily oral activities: systematic review/ meta-analysis. J Clin Periodontol. 2012;39(3):213-228. doi:10.1111/ j.1600-051X.2011.01784.x

14. Obinata H, Hla T. Sphingosine 1-phosphate and inflammation. Int Immunol. 2019;31(9):617-625. doi:10.1093/intimm/dxz037

15. Stepanovska B, Huwiler A. Targeting the S1P receptor signaling pathways as a promising approach for treatment of autoimmune and inflammatory diseases. Pharmaco Res. 2020;154:104170. doi:10.1016/j.phrs.2019.02.009

16. Spiegel S, Milstien S. Sphingosine-1-phosphate: an enigmatic signalling lipid. Nat Rev Mol Cell Biol. 2003;4(5):397-407. doi:10.1038/ nrm1103

17. Blaho VA, Hla T. An update on the biology of sphingosine 1-phosphate receptors. J Lipid Res. 2014;55(8):1596-1608. doi: $10.1194 /$ jlr.R046300

18. Rosen H, Stevens RC, Hanson M, Roberts E, Oldstone MBA. Sphingosine-1-phosphate and its receptors: structure, signaling, and influence. Annu Rev Biochem. 2013;82(1):637-662. doi:10.1146/ annurev-biochem-062411-130916

19. Bode C, Sensken S-C, Peest U, et al. Erythrocytes serve as a reservoir for cellular and extracellular sphingosine 1-phosphate. J Cell Biochem. 2010;109(6):1232-1243. doi:10.1002/jcb.22507

20. Olivera A, Allende ML, Proia RL. Shaping the landscape: metabolic regulation of S1P gradients. Biochim Biophys Acta. 2013;1831 (1):193-202. doi:10.1016/j.bbalip.2012.06.007 
21. Ulrych T, Böhm A, Polzin A, et al. Release of sphingosine-1-phosphate from human platelets is dependent on thromboxane formation. J Thromb Haemost. 2011;9(4):790-798. doi:10.1111/j.1538-7836.2011.04194.x

22. Soltau I, Mudersbach E, Geissen M, et al. Serum-sphingosine1-phosphate concentrations are inversely associated with atherosclerotic diseases in humans. PLoS One. 2016;11(12):e0168302. doi:10.1371/journal.pone. 0168302

23. Winkler MS, Nierhaus A, Holzmann M, et al. Decreased serum concentrations of sphingosine-1-phosphate in sepsis. Critical Care. 2015;19(1):372. doi:10.1186/s13054-015-1089-0

24. Moritz E, Wegner D, Groß S, et al. Reference intervals for serum sphingosine-1-phosphate in the population-based study of health in Pomerania. Clin Chim Acta. 2017;468:25-31. doi:10.1016/j. cca.2017.01.029

25. Moritz E, Wegner D, Groß S, et al. Data on subgroup specific baseline characteristics and serum sphingosine-1-phosphate concentrations in the Study of Health in Pomerania. Data Brief. 2017;12:46-50. doi:10.1016/j.dib.2017.03.019

26. Ishii M, Kikuta J. Sphingosine-1-phosphate signaling controlling osteoclasts and bone homeostasis. Biochim Biophys Acta. 2013;1831(1):223-227. doi:10.1016/j.bbalip.2012.06.002

27. Weske S, Vaidya M, Reese A, et al. Targeting sphingosine-1-phosphate lyase as an anabolic therapy for bone loss Nat Med. 2018;24(5):667-678. doi:10.1038/s41591-018-0005-y

28. Völzke H, Alte D, Schmidt CO, et al. Cohort profile: the study of health in Pomerania. Int $J$ Epidemiol. 2011;40(2):294-307. doi:10.1093/ije/dyp394

29. Völzke H, Ittermann T, Schmidt CO, et al. Prevalence trends in lifestyle-related risk factors. Dtsch Arztebl Int. 2015;112 (11):185-192. doi:10.3238/arztebl.2015.0185

30. Poul Erik Petersen, Ramon J Baez, World Health Organization. Citation: Petersen PE, Ramon RJ \& World Health Organization. Oral health surveys: basic methods, 5th ed. Geneva:World Health Organisation;2013

31. Demmer RT, Kocher T, Schwahn C, Völzke H, Jacobs Jr DR, Desvarieux M. Refining exposure definitions for studies of periodontal disease and systemic disease associations. Community Dent Oral Epidemiol. 2008;36(6):493-502. doi:10.1111/j.16000528.2008.00435.x

32. Holtfreter B, Albandar JM, Dietrich T, et al. Standards for reporting chronic periodontitis prevalence and severity in epidemiologic studies: proposed standards from the Joint EU/USA periodontal epidemiology working group. $J$ Clin Periodontol. 2015;42(5):407-412. doi:10.1111/jepe. 12392

33. Page RC, Eke PI. Case definitions for use in population-based surveillance of periodontitis. $J$ Periodontol. 2007;78(7 Suppl):1387-1399. doi:10.1902/jop.2007.060264

34. Meisel P, Giebel J, Peters M, et al. Expression of N-acetyltransferases in periodontal granulation tissue. J Dent Res. 2002;81(5):349-353. doi: $10.1177 / 154405910208100512$

35. Meisel P, Pink C, Pitchika V, Nauck M, Völzke H, Kocher T. Competing interplay between systemic and periodontal inflammation: obesity overrides the impact of oral periphery. Clin Oral Investig. 2020

36. Pink C, Kocher T, Meisel P, et al. Longitudinal effects of systemic inflammation markers on periodontitis. J Clin Periodontol. 2015;42 (11):988-997. doi:10.1111/jcpe.12473

37. Gocke C, Holtfreter B, Meisel P, et al. Abdominal obesity modifies long-term associations between periodontitis and markers of systemic inflammation. Atherosclerosis. 2014;235(2):351-357. doi:10.1016/j. atherosclerosis.2014.05.926

38. Allende ML, Bektas M, Lee BG, et al. Sphingosine-1-phosphate lyase deficiency produces a pro-inflammatory response while impairing neutrophil trafficking. J Biol Chem. 2011;286(9):7348-7358. doi:10.1074/jbc.M110.171819
39. Ledgerwood LG, Lal G, Zhang N, et al. The sphingosine 1-phosphate receptor 1 causes tissue retention by inhibiting the entry of peripheral tissue T lymphocytes into afferent lymphatics. Nat Immunol. 2008;9 (1):42-53. doi:10.1038/ni1534

40. Xiao L, Zhou Y, Friis T, Beagley K, Xiao Y. S1P-S1PR1 signaling: the "Sphinx" in osteoimmunology. Front Immunol. 2019;10:1409. doi:10.3389/fimmu.2019.01409

41. Mahajan-Thakur S, Böhm A, Jedlitschky G, Schrör K, Rauch BH. Sphingosine-1-phosphate and its receptors: a mutual link between blood coagulation and inflammation. Mediators Inflamm. 2015;2015:831059. doi:10.1155/2015/831059

42. Kim E-S, Cha Y, Ham M, et al. Inflammatory lipid sphingosine1-phosphate upregulates C-reactive protein via C/EBP $\beta$ and potentiates breast cancer progression. Oncogene. 2014;33(27):3583-3593. doi:10.1038/onc.2013.319

43. Bougault C, El Jamal A, Briolay A, et al. Involvement of sphingosine kinase/sphingosine 1-phosphate metabolic pathway in spondyloarthritis. Bone. 2017;103:150-158. doi:10.1016/j.bone.2017.07.002

44. Choi HS, Kim KH, Jin S, et al. Decreased expression of sphingosine-1-phosphate receptor 1 in the blood leukocyte of rheumatoid arthritis patients. Immune Netw. 2018;18(5):e39. doi:10.4110/ in.2018.18.e39

45. Böhm A, Flößer A, Ermler S, et al. Factor-Xa-induced mitogenesis and migration require sphingosine kinase activity and S1P formation in human vascular smooth muscle cells. Cardiovasc Res. 2013;99 (3):505-513. doi:10.1093/cvr/cvt112

46. Halin C, Scimone ML, Bonasio R, et al. The S1P-analog FTY720 differentially modulates T-cell homing via HEV: t-cell-expressed S1P1 amplifies integrin activation in peripheral lymph nodes but not in Peyer patches. Blood. 2005;106(4):1314-1322. doi:10.1182/ blood-2004-09-3687

47. Maceyka M, Spiegel S. Sphingolipid metabolites in inflammatory disease. Nature. 2014;510(7503):58-67. doi:10.1038/nature13475

48. Schwab SR, Cyster JG. Finding a way out: lymphocyte egress from lymphoid organs. Nat Immunol. 2007;8(12):1295-1301. doi:10.1038/ ni1545

49. Kułakowska A, Zendzian-Piotrowska M, Baranowski M, et al. Intrathecal increase of sphingosine 1-phosphate at early stage multiple sclerosis. Neurosci Lett. 2010;477(3):149-152. doi:10.1016/j. neulet.2010.04.052

50. Snider AJ, Kawamori T, Bradshaw SG, et al. A role for sphingosine kinase 1 in dextran sulfate sodium-induced colitis. FASEB J. 2009;23 (1):143-152. doi:10.1096/fj.08-118109

51. Liang J, Nagahashi M, Kim EY, et al. Sphingosine-1-phosphate links persistent STAT3 activation, chronic intestinal inflammation, and development of colitis-associated cancer. Cancer Cell. 2013;23 (1):107-120. doi:10.1016/j.ccr.2012.11.013

52. Suh JH, Saba JD. Sphingosine-1-phosphate in inflammatory bowel disease and colitis-associated colon cancer: the fat's in the fire. Transl Cancer Res. 2015;4(5):469-483. doi:10.3978/j.issn.2218-676X.2015.10.06

53. Lai W-Q, Irwan AW, Goh HH, et al. Anti-inflammatory effects of sphingosine kinase modulation in inflammatory arthritis. $J$ Immunol. 2008;181(11):8010-8017. doi:10.4049/jimmunol.181.11.8010

54. Kitano M, Hla T, Sekiguchi M, et al. Sphingosine 1-phosphate/ sphingosine 1-phosphate receptor 1 signaling in rheumatoid synovium: regulation of synovial proliferation and inflammatory gene expression. Arthritis Rheum. 2006;54(3):742-753. doi:10.1002/ art.21668

55. Eskan MA, Rose BG, Benakanakere MR, Lee M-J, Kinane DF. Sphingosine 1-phosphate 1 and TLR4 mediate IFN-beta expression in human gingival epithelial cells. $J$ Immunol. 2008;180 (3):1818-1825. doi:10.4049/jimmunol.180.3.1818

56. Eskan MA, Rose BG, Benakanakere MR, et al. TLR4 and S1P receptors cooperate to enhance inflammatory cytokine production in human gingival epithelial cells. Eur $J$ Immunol. 2008;38 (4):1138-1147. doi:10.1002/eji.200737898 
57. Yu H, Sun C, Argraves KM. Periodontal inflammation and alveolar bone loss induced by Aggregatibacter actinomycetemcomitans is attenuated in sphingosine kinase 1-deficient mice. J Periodontal Res. 2016;51(1):38-49. doi:10.1111/jre.12276

58. Yu H, Herbert BA, Valerio M, Yarborough L, Hsu L-C, Argraves KM. FTY720 inhibited proinflammatory cytokine release and osteoclastogenesis induced by Aggregatibacter actinomycetemcomitans. Lipids Health Dis. 2015;14(1):66. doi:10.1186/s12944-015-0057-7

59. Lee D-E, Kim J-H, Choi S-H, Cha J-H, Bak E-J, Yoo Y-J. The sphingosine-1-phosphate receptor 1 binding molecule FTY720 inhibits osteoclast formation in rats with ligature-induced periodontitis. J Periodontal Res. 2017;52(1):33-41. doi:10.1111/jre.12366

60. Lucaciu A, Brunkhorst R, Pfeilschifter JM, Pfeilschifter W, Subburayalu J. The S1P-S1PR Axis in neurological disorders-insights into current and future therapeutic perspectives. Cells. 2020;9(6):1515. doi:10.3390/cells9061515

61. Han M, Sun T, Chen H, Han M, Wang D. Potential sphingosine-1-phosphate-related therapeutic targets in the treatment of cerebral ischemia reperfusion injury. Life Sci. 2020;249:117542. doi:10.1016/j.lfs.2020.117542

62. Zhang L, Dong Y, Wang Y, Hu W, Dong S, Chen Y. Sphingosine1-phosphate (S1P) receptors: promising drug targets for treating bone-related diseases. J Cell Mol Med. 2020;24(8):4389-4401. doi: $10.1111 /$ jcmm. 15155
63. Ardawi M-SM, Rouzi AA, Al-Senani NS, Qari MH, Elsamanoudy AZ, Mousa SA. High plasma sphingosine 1-phosphate levels predict osteoporotic fractures in postmenopausal women: the center of excellence for osteoporosis research Study.. J Bone Metab. 2018;25(2):87-98. doi:10.11005/jbm.2018.25.2.87

64. Pchejetski D, Bohler T, Brizuela L, et al. FTY720 (fingolimod) sensitizes prostate cancer cells to radiotherapy by inhibition of sphingosine kinase-1. Cancer Res. 2010;70(21):8651-8661. doi:10.1158/ 0008-5472.CAN-10-1388

65. Tonelli F, Lim KG, Loveridge C, et al. FTY720 and (S)-FTY720 vinylphosphonate inhibit sphingosine kinase 1 and promote its proteasomal degradation in human pulmonary artery smooth muscle, breast cancer and androgen-independent prostate cancer cells. Cell Signal. 2010;22(10):1536-1542. doi:10.1016/j.cellsig.2010.05.022

66. Vessey DA, Kelley M, Zhang J, Li L, Tao R, Karliner JS. Dimethylsphingosine and FTY720 inhibit the SK1 form but activate the SK2 form of sphingosine kinase from rat heart. $J$ Biochem Mol Toxicol. 2007;21(5):273-279. doi:10.1002/jbt.20193
Journal of Inflammation Research

\section{Publish your work in this journal}

The Journal of Inflammation Research is an international, peerreviewed open-access journal that welcomes laboratory and clinical findings on the molecular basis, cell biology and pharmacology of inflammation including original research, reviews, symposium reports, hypothesis formation and commentaries on: acute/chronic inflammation; mediators of inflammation; cellular processes; molecular
Dovepress

mechanisms; pharmacology and novel anti-inflammatory drugs; clinical conditions involving inflammation. The manuscript management system is completely online and includes a very quick and fair peerreview system. Visit http://www.dovepress.com/testimonials.php to read real quotes from published authors. 